BMJ Open

Sport \&

Exercise

Medicine

\title{
Rehabilitation interventions need more than methodological standardisation: an individualised approach
}

\author{
Neil Welch (D), ${ }^{1,2}$ Chris Richter, ${ }^{1}$ Kieran Moran, ${ }^{3,4}$ Andy Franklyn-Miller ${ }^{1,5}$
}

To cite: Welch N, Richter C, Moran $\mathrm{K}$, et al. Rehabilitation interventions need more than methodological standardisation: an individualised approach. BMJ Open Sport \& Exercise Medicine 2020;0:e000899. doi:10.1136/ bmjsem-2020-000899

- Supplemental material is published online only. To view please visit the journal online (http://dx.doi.org/10.1136/ bmjsem-2020-000899).

Received 15 July 2020 Revised 2 October 2020 Accepted 18 October 2020
Check for updates

(C) Author(s) (or their employer(s)) 2020. Re-use permitted under CC BY-NC. No commercial re-use. See rights and permissions. Published by BMJ.

${ }^{1}$ Sports Medicine, Sports Surgery Clinic, Dublin, Ireland ${ }^{2}$ INSIGHT Research Centre, Dublin City University, Dublin, Ireland

${ }^{3}$ School of Health and Human Performance, Dublin City University, Dublin, Ireland ${ }^{4}$ Human Sensing, INSIGHT Research Centre, Dublin, Ireland ${ }^{5}$ Centre for Health, Exercise and Sports Medicine, University of Melbourne, Melbourne, Australia

\section{Correspondence to}

Neil Welch;

neilwelch@sportssurgeryclinic. com

\section{ABSTRACT}

Objectives: The main aim in the current study was to use a single-subject analysis to profile the physical performance characteristics of individuals within an injured group and a between-group approach to profile the group as a whole. These profiles were then used to inform single-subject and between-group rehabilitation interventions. Methods: Fiftythree (28 with athletic groin pain and 25 non-injured) Gaelic football players (24.8 years \pm 7.1 years; $179 \mathrm{~cm} \pm 5.5 \mathrm{~cm}$; $79.7 \mathrm{~kg} \pm 9.2 \mathrm{~kg}$ ) underwent 3D biomechanical analysis, which was used to measure a series of physical performance characteristics. The non-injured group was used to create a 'performance database' to compare the injured individuals, and a between-group analysis was also conducted. The scores from each analysis were used to inform the targets of interventions. Results: The analysis highlighted the variety of profiles that existed across the tested individuals and that these profiles differed from that of the between-group analysis. By analysing individuals in a single-subject approach, detail can be seen that is lost with between-group analysis.

\section{OBJECTIVES}

Most studies, whether interventional or observational in musculoskeletal medicine and sports science take a between-group analysis approach. Observational studies attempt to understand the differences between those with and without an injury to determine association or causation and, subsequently, potential targets for rehabilitation. ${ }^{1-3}$ Intervention studies test an intervention using a selected primary outcome measure, typically improvement of symptoms. ${ }^{4-6}$ The mean changes in the physical performance characteristics are then used to judge the effectiveness of interventions. The interventions are commonly standardised across all subjects using guidelines such as PREPARE and SPIRIT to ensure consistency. ${ }^{78}$

A between-group analysis approach is taken to average out variability between individuals and measurement error among large groups, and to better understand mean effects. However, this may make it difficult to understand if variability between individuals is due to the presence of distinct movement patterns and

\section{Summary}

- A single-subject approach can show detail that is lost in a between-group approach.

- Within each task, a large variety of physica performance characteristics were observed across the analysed individuals.

- None of the single-subject profile interventions was the same as the between-group intervention.

may lead to such distinct patterns being overlooked. Bates ${ }^{9}$ advocates the use of singlesubject approaches treating each individual as unique to overcome this. It is rare in research studies for single-subject approaches to be taken in sports science and medicine due to the emphasis placed on betweengroup approaches described above. Betweengroup approaches require larger participant numbers to appropriately power statistical analysis creating greater difficulty in presenting single-subject results. However, singlesubject analysis has highlighted findings that would have been masked by between-group analysis in non-injured populations. ${ }^{9-11}$ It is yet to be applied to understand the variation among individuals in injured populations in respect to an intervention. Efforts should be made to understand if single-subject analysis offers alternative insight for practitioners and its usefulness in informing intervention studies.

Single-subject approaches are common in the elite sporting environment where performance is the primary outcome. Testing is used to create a profile of physical performance characteristics allowing for the individualisation of exercise interventions. ${ }^{12}$ To obtain the kinetic and kinematic data for creating such a profile, force plate and 3D biomechanical testing are the gold standard. As an example, for profiling acceleration in two field sports athletes, one may demonstrate low ankle stiffness that limits force transfer to the ground while the other may demonstrate poor hip 
extension strength necessary to overcome inertia. Therefore, the same intervention applied to both athletes could have differed or even no effect for each athlete.

Athletic groin pain is a chronic musculoskeletal condition that is common among athletes participating in field sports. ${ }^{13}$ Faster return to play rates have been observed in those undertaking rehabilitation compared to surgery ${ }^{14}$ indicating a role for rehabilitation. A broad range of physical performance characteristics, the target of rehabilitation interventions, have been associated with athletic groin pain including strength, ${ }^{1}$ reactive strength ${ }^{15}$ and change of direction biomechanics. ${ }^{16}$ Given the broad range of physical performance characteristics related to athletic groin pain, a single-subject approach may offer insight into the variation that exists between individuals.

The current study aims to use a single-subject approach to profile the physical performance characteristics of individuals within an injured group and a betweengroup approach to profile the group as a whole. We will then use those profiles to inform single-subject and between-group rehabilitation interventions. We hypothesise that the rehabilitation interventions that would be informed by the single-subject approach will be different by that informed by the between-group approach.

\section{METHODS}

\section{Participants}

Fifty-three male Gaelic football players (24.8 years \pm 7.1 years; $179 \mathrm{~cm} \pm 5.5 \mathrm{~cm} ; 79.7 \mathrm{~kg} \pm 9.2 \mathrm{~kg}$ ) gave their consent to be participants in this single-subject design exploratory study. Testing was approved by the Sports Surgery Clinic Ethics Board (ref: 0017). All participants were amateur but consistently trained for their sport four to six times per week and had a resistance training history greater than 2 years. They were divided into two groups: the first a non-injured group consisting of 25 participants, with no athletic groin pain, the second consisting of 28 field sport athletes who were attending a large Sports Medicine Clinic to undergo structured rehabilitation for athletic groin pain. The athletic groin pain group reported unilateral pain in the anterior hip and groin area while playing Gaelic football with symptom duration longer than 4 weeks. Participants were excluded if deemed to have hip joint arthrosis [grade 3 or higher on $\mathrm{MRI}^{17}$ ] or had an underlying medical condition such as inflammatory arthropathy or infection.

\section{Procedures}

A ten-camera motion analysis system (Bonita B10, Vicon, UK), synchronised with two $40 \times 60 \mathrm{~cm}$ force platforms (BP400600, AMTI, USA) was used to collect kinetic and kinematic data for physical performance characteristics in tests of cutting, maximum strength, explosive strength, deceleration and reactive strength $\left(45^{\circ}\right.$ and $110^{\circ}$ cuts, isometric mid-thigh pull (IMTP), single-leg squat jump (SLSJ), single-leg drop landing (SLDL) and single-leg drop jump (SLDJ), respectively). The Vicon Plug-in-Gait marker set was used as per Marshall et al. ${ }^{18}$ Twenty-four reflective markers were placed on bony landmarks at the lower limb, pelvis and trunk. Simultaneous kinematic and kinetic data $(200 \mathrm{~Hz}, 2000 \mathrm{~Hz})$ were collected using a software package (Nexus 2, Vicon Motion Systems, UK). These data were filtered using a fourth-order low-pass Butterworth filter (cut-off frequency $15 \mathrm{~Hz}$ ).${ }^{19}$ All ground reaction force (GRF) data were normalised to participant's bodyweight. All participants completed a standardised warm-up consisting of 2-min jogging, five forward, backward and lateral lunges on each leg, eight deep squats and five countermovement jumps. The order of which limb was tested first was randomised but remained consistent throughout all of the tests. The testing order is displayed in figure 1 . The physical performance characteristics selected can be seen in table 1 . These were selected as they have been associated with high levels of performance in the tasks themselves ${ }^{20-22}$ or associated with cutting performance. ${ }^{18} 2324$ Three trials were performed on each leg by each participant. Procedures for these tests and how the variables were calculated have been detailed elsewhere. ${ }^{22}$

\section{Statistics}

The non-injured group was used to create a 'performance database' to compare the injured individuals to. All of the trials were used from all the participants with the minimum value subtracted from the maximum value to create the range of values. This range of each physical performance characteristic was then normalised to 100 data points. Each of the best physical performance characteristics from the injured group, regardless of leg for the

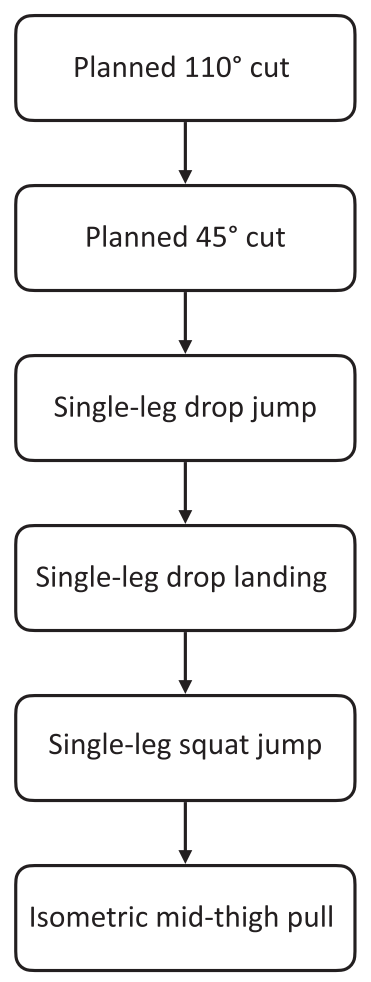

Figure 1 Order of biomechanical testing. 
Table 1 Physical performance characteristics of interest in each of the biomechanical tests

\begin{tabular}{|c|c|}
\hline Exercise & Variable \\
\hline $110^{\circ}$ cut & $\begin{array}{l}\text { Completion time, ground contact time, } \\
\text { horizontal to vertical ratio }\end{array}$ \\
\hline $45^{\circ}$ cut & $\begin{array}{l}\text { Completion time, ground contact time, } \\
\text { horizontal to vertical ratio }\end{array}$ \\
\hline Drop-jump & Ground contact time, jump height \\
\hline Drop-landing & $\begin{array}{l}\text { Time to stabilisation, impulse during the first } \\
50 \mathrm{~ms} \text {, vertical stiffness }\end{array}$ \\
\hline Squat-jump & $\begin{array}{l}\text { Jump time, jump height, impulse during the } \\
\text { first } 50 \mathrm{~ms}\end{array}$ \\
\hline IMTP & $\begin{array}{l}\text { Median force, RFD to peak force, RFD } \\
\text { during the first } 50 \mathrm{~ms}\end{array}$ \\
\hline
\end{tabular}

IMTP, Isometric mid-thigh pull; RFD, Rate of force development.

unilateral tests, was then compared to the normalised range to provide a score of performance with a score of 100 being the highest performing score. Shorter times (completion times, ground contact times, time to stabilisation and jump time) were judged as higher performing, all other physical performance characteristics as the larger the value, the higher the performance.

A decision was made to select five injured participants for analysis due to the difficulty in displaying individual data from all participants. An objective selection criterion was set by using the five participants with the largest Mahalanobis Distance to the non-injured performance database. The Mahalanobis distance (MD) was calculated for every subject within the injured group using the physical performance characteristics $\left(\mathrm{x}_{\mathrm{i}, \mathrm{n}}\right)$ to the average of the corresponding physical performance characteristics from the non-injured group $\left(\mu_{\mathrm{n}}\right)$ and was defined as:

$$
\operatorname{MD}\left(\mathrm{x}_{\mathrm{i}, \mathrm{n}}\right)=\sqrt{ }\left\{\left(\mathrm{x}_{\mathrm{i}, \mathrm{n}}-\mu_{\mathrm{n}}\right)^{\mathrm{T}} \cdot \mathrm{S}^{-1} \cdot\left(\mathrm{x}_{\mathrm{i}, \mathrm{n}}-\mu_{\mathrm{n}}\right)\right\}
$$

Where $\mathrm{n}$ is the row of the physical performance characteristic within the database, $i$ the subject, and $\mathrm{S}$ is the covariance matrix of the physical performance characteristics. All data used in this calculation are raw.

The authors recognise that the MD will be a novel measure for many readers. The MD is a measure of the distance from the centroid, which can be thought of as the overall mean for multiple variables. For example in the $110^{\circ}$ cut, it can be thought of as the overall mean of the completion time, the ground contact time and the horizontal to vertical ratio. The MDs for each injured individual are, using the example above, the distance of that individual's $110^{\circ}$ cut overall mean from the overall mean of the non-injured performance database of $110^{\circ}$ cuts. The MD was calculated for each of the tests which generated $6 \mathrm{MD}$ scores for each injured participant, one for each of the physical performance tests. A mean of the MDs was then calculated for each participant with the five largest mean MDs selected to be displayed within the results as the five participants that most differed from the performance database. These five participants will be hitherto referred to as the 'analysed' participants.

For the between-group analysis, a simulation approach was taken to understand the difference between injured and non-injured groups. This was done to make use of all of the collected trials rather than a mean of trials as is common in biomechanical analysis. In each simulation, one out of the three collected trials of the physical performance test was selected at random from each participant. For the noninjured group, this was selected at random from either limb. For the injured group, the trial was selected at random from trials of the injured limb (no participants reported pain on both sides). An independent sample T-test was performed to understand the size of the difference between groups. This process was repeated, or simulated, 100 times with the mean of the betweengroup differences used. Cohen's $d$ was used to denote effect size. Thresholds used were $0.2,0.6$ and 1.2 for small, moderate and large effects, respectively. ${ }^{25}$ The direction of the relationship of the effect size for each of the 100 T-tests run was also summed to add to interpretation. Data processing was carried out using the Python 2.7 programming language. To determine the impact that any difference between the singlesubject and between-group results might have on the design of rehabilitation interventions, cut-offs for physical performance characteristics were defined to denote inclusion as a target of an intervention. For the between-group analysis, any physical performance characteristic with an effect size of 0.6 was selected as cut-off based on Hopkins $e t a l^{25}$ determination that the effect size was moderate. For the single-subject analysis, a percentile score of 50 or below was selected as cut-off, this was selected as it is representative of being in the bottom half of all the tested scores. For ease, the latter cut-off will be referred to as a 'low percentile score'.

\section{RESULTS}

The Mahalanobis distances for each of the tested exercises for the analysed participants (P1-5) with the largest mean Mahalanobis distances are listed in table 2. The effect sizes for the between-group difference calculations for each of the physical performance characteristics are listed in table 3. The physical performance characteristics that would be targeted in interventions, based on the moderate effect size of 0.6 for the between-group analysis and a percentile score of less than 50 for the single-subject design are displayed in table 4 .

The physical performance characteristics that would be targeted by the intervention based on the assigned cutoffs for the between-group and single-subject approaches are listed in table 4.

Figure 2 and online supplemental files 1-5 illustrate the mean percentile score of the injured group alongside the individual percentile scores of the five largest MDs for the 
Table 2 Mahalanobis distances of the participants with the largest mean Mahalanobis distances for each of the tasks

\begin{tabular}{llcccccc}
\hline Participant & IMTP & SLSJ & SLDL & SLDJ & $\mathbf{1 1 0}^{\circ}$ cut & $\mathbf{4 5}^{\circ}$ cut & Participant mean MD \\
\hline P1 & 3.1 & 12.4 & 6.4 & 9.5 & 25.4 & 31.0 & 14.6 \\
P2 & 3.6 & 6.7 & 3.3 & 2.3 & 36.9 & 20.9 & 12.3 \\
P3 & 2.3 & 8.9 & 11.6 & 4.0 & 4.6 & 33.0 & 10.7 \\
P4 & 0.8 & 12.2 & 13.0 & 6.4 & 10.7 & 13.6 & 9.4 \\
P5 & 2.7 & 18.0 & 8.2 & 9.7 & 8.1 & 7.7 & 9.1 \\
\hline
\end{tabular}

IMTP, Isometric Mid-Thigh Pull; MD, Mahalanobis distance; SLSJ, Single-Leg Squat-Jump; SLDL, Single-Leg Drop-Landing; SLDJ, Single-Leg Drop-Jump.

\begin{tabular}{|c|c|c|c|}
\hline Variable & $d$ & Interpretation & * \\
\hline $\begin{array}{l}110^{\circ} \text { cut } \\
\text { completion time }\end{array}$ & 0.40 & $\begin{array}{l}\text { Non-injured completed } \\
\text { faster }\end{array}$ & 99 \\
\hline $110^{\circ}$ cut GCT & 0.19 & Non-injured shorter GCT & 98 \\
\hline $\begin{array}{l}110^{\circ} \text { cut } \\
\text { horizontal to } \\
\text { vertical ratio }\end{array}$ & 0.14 & $\begin{array}{l}\text { Non-injured had greater } \\
\text { horizontal to vertical GRF } \\
\text { ratio }\end{array}$ & 93 \\
\hline $\begin{array}{l}45^{\circ} \text { cut } \\
\text { completion time }\end{array}$ & 1.37 & $\begin{array}{l}\text { Non-injured completed } \\
\text { faster }\end{array}$ & 100 \\
\hline $45^{\circ}$ cut GCT & 0.76 & Non-injured shorter GCT & 100 \\
\hline $\begin{array}{l}45^{\circ} \text { cut horizontal } \\
\text { to vertical ratio }\end{array}$ & 0.44 & $\begin{array}{l}\text { Non-injured had greater } \\
\text { horizontal to vertical GRF } \\
\text { ratio }\end{array}$ & 95 \\
\hline SLDJ GCT & 0.43 & Non-injured shorter GCT & 100 \\
\hline $\begin{array}{l}\text { SLDJ Jump } \\
\text { height }\end{array}$ & -0.97 & $\begin{array}{l}\text { Non-injured greater jump } \\
\text { height }\end{array}$ & 100 \\
\hline $\begin{array}{l}\text { SLDL Time to } \\
\text { stabilisation }\end{array}$ & -0.33 & Non-injured longer time & 99 \\
\hline $\begin{array}{l}\text { SLDL Impulse } \\
\text { during the first } \\
50 \mathrm{~ms}\end{array}$ & -0.98 & $\begin{array}{l}\text { Non-injured greater } \\
\text { impulse }\end{array}$ & 100 \\
\hline $\begin{array}{l}\text { SLDL Vertical } \\
\text { stiffness }\end{array}$ & -0.29 & $\begin{array}{l}\text { Non-injured greater } \\
\text { stiffness }\end{array}$ & 99 \\
\hline SLSJ Jump time & -0.04 & $\begin{array}{l}\text { Non-injured greater jump } \\
\text { time }\end{array}$ & 55 \\
\hline $\begin{array}{l}\text { SLSJ Jump } \\
\text { height }\end{array}$ & -1.19 & $\begin{array}{l}\text { Non-injured greater jump } \\
\text { height }\end{array}$ & 100 \\
\hline $\begin{array}{l}\text { SLSJ Impulse } \\
\text { during the first } \\
50 \mathrm{~ms}\end{array}$ & -0.12 & $\begin{array}{l}\text { Non-injured greater } \\
\text { impulse }\end{array}$ & 71 \\
\hline $\begin{array}{l}\text { IMTP Median } \\
\text { force }\end{array}$ & -0.23 & $\begin{array}{l}\text { Non-injured greater } \\
\text { median force }\end{array}$ & 91 \\
\hline $\begin{array}{l}\text { IMTP RFD to } \\
\text { peak force }\end{array}$ & -0.35 & $\begin{array}{l}\text { Non-injured greater } \\
\text { median force }\end{array}$ & 91 \\
\hline $\begin{array}{l}\text { IMTP RFD during } \\
\text { the first } 50 \mathrm{~ms}\end{array}$ & -0.87 & $\begin{array}{l}\text { Non-injured greater } \\
\text { median force }\end{array}$ & 100 \\
\hline
\end{tabular}

*Number of simulations where the relationship is in one direction for example, for the $110^{\circ}$ cut completion time, 99 of the T-tests run resulted in the non-injured group completing the cuts faster than the injured group.

d, Cohen's d.

GCT, Ground contact time; IMTP, Isometric Mid-Thigh Pull; SLSJ, Single-Leg Squat-Jump; SLDL, Single-Leg Drop-Landing; SLDJ, Single-Leg Drop-Jump.
Table 4 Overview of which physical performance characteristics would be included in an intervention based on the defined cut-offs for between-group and single-subject analyses

\begin{tabular}{|c|c|c|c|c|c|c|}
\hline Variable & BG & P1 & $\mathbf{P 2}$ & P3 & P4 & P5 \\
\hline $110^{\circ}$ cut completion time & & & & $\checkmark$ & $\checkmark$ & $\checkmark$ \\
\hline $110^{\circ}$ cut GCT & & & & $\checkmark$ & $\checkmark$ & $\checkmark$ \\
\hline $\begin{array}{l}110^{\circ} \text { cut horizontal to vertical } \\
\text { ratio }\end{array}$ & & $\checkmark$ & & $\checkmark$ & & $\checkmark$ \\
\hline $45^{\circ}$ cut completion time & $\checkmark$ & $\checkmark$ & $\checkmark$ & & $\checkmark$ & $\checkmark$ \\
\hline $45^{\circ}$ cut $\mathrm{GCT}$ & $\checkmark$ & & & $\checkmark$ & $\checkmark$ & $\checkmark$ \\
\hline $\begin{array}{l}45^{\circ} \text { cut horizontal to vertical } \\
\text { ratio }\end{array}$ & & & $\checkmark$ & $\checkmark$ & & $\checkmark$ \\
\hline SLDJ GCT & & & $\checkmark$ & $\checkmark$ & & \\
\hline SLDJ Jump height & $\checkmark$ & $\checkmark$ & $\checkmark$ & $\checkmark$ & $\checkmark$ & $\checkmark$ \\
\hline SLDL Time to stabilisation & & $\checkmark$ & & & $\checkmark$ & $\checkmark$ \\
\hline $\begin{array}{l}\text { SLDL Impulse during the first } \\
50 \mathrm{~ms}\end{array}$ & $\checkmark$ & & $\checkmark$ & & & $\checkmark$ \\
\hline SLDL Vertical stiffness & & $\checkmark$ & & & & $\checkmark$ \\
\hline SLSJ Jump time & & $\checkmark$ & $\checkmark$ & $\checkmark$ & & \\
\hline SLSJ Jump height & $\checkmark$ & $\checkmark$ & $\checkmark$ & $\checkmark$ & & $\checkmark$ \\
\hline $\begin{array}{l}\text { SLSJ Impulse during the first } \\
50 \mathrm{~ms}\end{array}$ & & & $\checkmark$ & & $\checkmark$ & $\checkmark$ \\
\hline IMTP Median force & & $\sqrt{ }$ & $\checkmark$ & $\checkmark$ & $\checkmark$ & $\checkmark$ \\
\hline IMTP RFD to peak force & & $\checkmark$ & $\checkmark$ & $\checkmark$ & $\checkmark$ & $\checkmark$ \\
\hline $\begin{array}{l}\text { IMTP RFD during the first } \\
50 \mathrm{~ms}\end{array}$ & $\checkmark$ & $\checkmark$ & $\checkmark$ & & & $\checkmark$ \\
\hline
\end{tabular}

BG, Between-group analysis; GCT, Ground contact time; IMTP, Isometric Mid-Thigh Pull; P1, Participant 1; P2, Participant 2; P3, Participant 3; P4, Participant 4; P5, Participant 5; SLSJ, Single-Leg Squat-Jump; SLDL, Single-Leg Drop-Landing; SLDJ, Single-Leg Drop-Jump.

IMTP, the single-leg squat-jump, the single-leg droplanding, the single-leg drop-jump, the $110^{\circ}$ cut and the $45^{\circ}$ cut, respectively.

\section{DISCUSSION}

\section{Findings}

The primary aim of the current study was to use a singlesubject approach to profile the physical performance characteristics using kinematic and kinetic assessment of individuals within an injured group and between-group approach to profile the group as a whole. 
Individual profiles of the IMTP

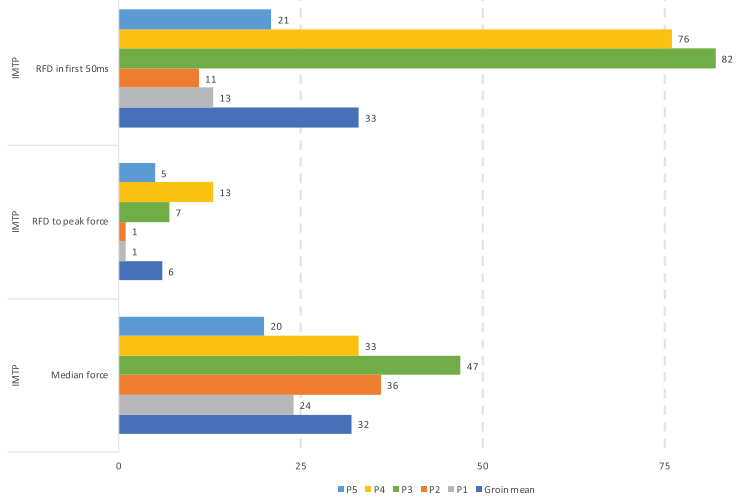

Figure 2 Individual profiles of IMTP.

It can be observed in figure 2 and online supplemental files $1-5$, the complexity of differentiation that exists in the profiles of the physical performance characteristics, of those patients presenting with athletic groin pain across a range of tasks. In this instance, with the use of cut-offs to assist in deciding upon targets of rehabilitation, table 4 highlights the difference between individuals and the group as a whole. By using a single-subject approach in intervention design, rehabilitation can be personalised more effectively at an intervention level.

Within the IMTP (figure 2; table 4), if the betweengroup analysis is considered, the only variable with a moderate or above effect size (our a priori size for inclusion in an intervention) is rate of force development in the first $50 \mathrm{~m}(d=-0.87)$. In consequence, this would be the sole target of an intervention of the variables of interest within the IMTP as median force $(d=-0.23)$, which represents strength, and rate of force development to peak force $(d=-0.35)$ do not reach moderate effect sizes. However, the analysed participants all demonstrated a different profile from the between-group analysis, with low percentile scores for strength (median force) indicating they would likely benefit from some increase in strength. In addition, $\mathrm{P} 3$ and $\mathrm{P} 4$ had much higher rates of force development in the first $50 \mathrm{~ms}$ (82 and 76 percentile, respectively) suggesting that they are likely to benefit less from a rate for force development intervention than the other participants, due to the principle of diminishing returns. This principle suggests that previously welltrained athletes have limited ability to progress their strength levels, ${ }^{26}$ muscle size ${ }^{27}$ and explosive strength. ${ }^{28}$ Cormie $e t a l^{28}$ suggest that targeting the least developed factors will result in the greatest adaptation and thus have the greatest impact on performance. This last point would clearly not be the case for the analysed participants if the between-group analysis profile is used to dictate intervention design and would potentially result in a limited adaptive response from such an intervention. In this instance, the use of a between-group approach would lead to the one consistent low variable, strength, for all of the analysed participants not being addressed in an intervention.
Similar observations can be observed within the profiles of the other tasks (online supplemental files 1-5). When observed for all of the physical performance characteristics together (table 4 ), the between-group profile-based interventions differ from all the profile-based interventions for the analysed individuals.

\section{Broader context}

When considering a single-subject approach in the context of the rehabilitation literature, it is possible to find areas for improvement in analysis. For example, the UK FASHIoN trial ${ }^{29}$ demonstrated improved outcomes following surgery over a conservative intervention, in those with femoro-acetabular impingement (FAI). However, the exercise intervention, ${ }^{30}$ was not based on assessing and targeting individual deficits, rather a generalised perception of group deficit was used by clinicians. ${ }^{30}$ Further, the effectiveness of the intervention on strength was not measured, so it is unknown whether the intervention stimulated any adaptive responses. If instead, individuals were allocated to interventions based on their profiling requirements and measured post-intervention to determine if the intervention was effective, there would be much greater confidence in stating that arthroscopy is more effective in reducing pain. This is important as large trials such as this example guide decision making in practice.

In another example, Thorborg et $a l^{1}$ used a betweengroup approach concluding that those with hip adductorrelated groin pain demonstrated lower eccentric hip adductor strength than a non-injured group. It was logically concluded that exercises to target eccentric hip adductor strength should be employed in those with adductor-related groin pain. To the practitioner, this confers an idea of one specific area of hip strengthening to target all those presenting with adductor-related pain. However, without the use of a single-subject approach it is impossible to know whether some of those participants had profiles with weak hip abduction and hip flexion, or had high levels of hip adductor strength, and would have benefitted more from a different intervention. The potential issues with a between-group approach extend to the rehabilitation interventions. In a systematic review, Charlton $e t a l^{31}$ concluded that hip and abdominal exercises involving external load may lead to favourable outcomes in athletic groin pain. Of the 12 studies included, three randomised controlled studies and nine case series, only one (a single case presentation) used the profile taken during assessment to guide the intervention. It is therefore possible that the interventions applied are not the most appropriate to individuals and therefore blunt the effect. For example, abdominal exercises using external load may be very effective for those with weak abdominals but not for those who already have high levels of strength in that area.

To understand the effects of the applied interventions, the measurement of pre- and post-intervention physical performance characteristics is required. Bennell et $a \tilde{l}$ 
found that a 12-week exercise intervention incorporating hip abductor and quadriceps strengthening, manual therapy, stretching, functional balance and gait training was no more beneficial than a sham treatment on pain and function in those with hip osteoarthritis. Pre- and postintervention analysis of physical performance characteristics of strength, range of motion, balance and walking speed suggested no greater changes in those outcomes, bar balance, between-groups. In this instance, all participants were given hip abduction and quad strengthening exercises. Without the use of single-subject analysis it is not possible to determine if the lack of between-group differences were due to inappropriately targeted interventions or if the interventions were not designed in a way to stimulate adaptive responses.

To date, our understanding of rehabilitation and response to exercise interventions owes much to the use of standardised interventions and between-group analysis. However, work is limited on the physical performance characteristics that represents the individual. The variety observed using the single-subject approach cannot be overlooked, the risk being that response to interventions and our understanding of rehabilitation is blunted. The current study represents a starting point from which to develop understanding of the individual impact of injury and responses to rehabilitation.

\section{Limitations}

Certain tasks and physical performance characteristics were selected for observation based on their relationship with performance outcomes. However, the appropriateness and relevance of these variables to the rehabilitation of those with athletic groin pain requires testing to determine if improvements in the selected physical performance characteristics play a role in rehabilitation from athletic groin pain. Athletic groin pain patients commonly present with several areas of pain which do not always correlate with abnormal signal on MRI, ${ }^{32}$ it is not known if pain could lead to specific changes in physical performance characteristics. Further study is required to understand if this occurs and should seek to apply to the same approach to more homogenous groups. Future work should also consider whether the effectiveness of rehabilitation interventions is enhanced using individualised physical performance characteristic profiles.

\section{CONCLUSION}

By analysing physical performance characteristics in a single-subject approach, detail can be seen that is lost with between-group analysis. This allows for the design of targeted interventions which may affect positively, or negatively, the outcome of rehabilitation. The authors question the wider applicability of the use of betweengroup data on its own in rehabilitation studies, as this may reduce the mean response in all, and slow the rehabilitation response in others. Adoption of such an approach would give practitioners a methodological rationale for the design of individualised interventions and to better understand the effectiveness of interventions for stimulating adaptive response in participants. It also allows for scrutiny of the effectiveness of interventions if the same approach is used for follow-up testing. In practice, clinicians attempt to find the deficiencies in physical performance characteristics but are often limited by time and facilities among other factors. Attempting to determine biomechanical issues with more specific diagnostic testing would assist the practitioner in understanding the individual response to interventions and the efficacy of applying them in practice.

\section{Twitter Neil Welch @nwconditioning.}

Acknowledgements The authors would like to thank Associate Professor Dominik Liebl for his guidance on the statistical testing employed in the methods for this study. We would also like to thank friends and colleagues at the Sports Surgery Clinic for their support and assistance that goes into all of the work that we do.

Contributors NW Primary author involved in all aspects of data; C R Assisted with data analysis and coding for statistical testing along with collaborating with the group on multiple drafts of the article; KM PhD supervisor for NW during which this study data were collected assisted the group in writing multiple drafts of the article; AF-M Assisted with the research design and the overall direction of the article and was involved in the review of multiple drafts of the article.

Funding This research received no specific grant from an funding agency in the public, commercial or not-for-profit sectors.

Competing interests None declared.

Provenance and peer review Not commissioned; externally peer reviewed.

Data availability statement All data relevant to the study are included in the article or uploaded as supplemental information.

Supplemental material This content has been supplied by the author(s). It has not been vetted by BMJ Publishing Group Limited (BMJ) and may not have been peerreviewed. Any opinions or recommendations discussed are solely those of the author(s) and are not endorsed by BMJ. BMJ disclaims all liability and responsibility arising from any reliance placed on the content. Where the content includes any translated material, BMJ does not warrant the accuracy and reliability of the translations (including but not limited to local regulations, clinical guidelines, terminology, drug names and drug dosages), and is not responsible for any error and/or omissions arising from translation and adaptation or otherwise.

Open access This is an open access article distributed in accordance with the Creative Commons Attribution Non Commercial (CC BY-NC 4.0) license, which permits others to distribute, remix, adapt, build upon this work non-commercially, and license their derivative works on different terms, provided the original work is properly cited, appropriate credit is given, any changes made indicated, and the use is non-commercial. See: http://creativecommons.org/licenses/by-nc/4.0/.

\section{ORCID iD}

Neil Welch http://orcid.org/0000-0001-6678-6198

\section{REFERENCES}

1 Thorborg K, Branci S, Nielsen MP, et al. Eccentric and isometric hip adduction strength in male soccer players with and without adductor-related groin pain: an assessor-blinded comparison. Orthop J Sport Med 2014;2:1-7.

2 Petersen W, Taheri P, Forkel P, et al. Return to play following ACL reconstruction : a systematic review about strength deficits. Arch Orthop Trauma Surg 2014;134:1417-28.

3 Mirkov DM, Knezevic OM, Maffiuletti NA, et al. Contralateral limb deficit after ACL-reconstruction: an analysis of early and late phase of rate of force development. J Sports Sci 2016;0414:1-6.

4 Alfredson $\mathrm{H}$, Pietilä T, Jonsson P, et al. Heavy-load eccentric calf muscle training for the treatment of chronic Achilles tendinosis. Am J Sports Med 1998;26:360-6.

5 Bennell KL, Egerton T, Martin J, et al. Effect of physical therapy on pain and function in patients with hip osteoarthritis a randomized clinical trial. JAMA 2014;311:1987-97. 
6 Welch N, Moran K, Antony J, et al. The effects of a free-weight-based resistance training intervention on pain, squat biomechanics and MRI-defined lumbar fat infiltration and functional cross-sectional area in those with chronic low back pain. BMJ Open Sport Exerc Med 2015;1:1-10.

7 Chan AW, Tetzlaff JM, Altman DG, et al. Spirit 2013 statement: defining standard protocol items for clinical trials. Chinese J Evidence-Based Med 2013;13:1501-7.

8 Bandholm T, Christensen R, Thorborg K, et al. Preparing for what the reporting checklists will not tell you: the PREPARE trial guide for planning clinical research to avoid research waste. Br J Sports Med 2017:51:1494-501.

9 Bates BT. Single-subject methodology: an alternative approach. Med Sci SportExerc 1996;28:631-8.

10 Stergiou N, Scott MM. Baseline measures are altered in biomechanical studies. J Biomech 2005;38:175-8.

11 Stergiou N, Bates BT. The relationship between subtalar and knee joint function as a possible mechanism for running injuries. Gait Posture 1997;6:177-85.

12 Mcguigan MR, Cormack SJ, Gill ND. Strength and power profiling of athletes: selecting test and how to use the information for program design. Strength Cond J 2013;35:7-14.

13 Waldén M, Hägglund M, Ekstrand J. The epidemiology of groin injury in senior football: a systematic review of prospective studies. Br J Sports Med 2015;49:792-7.

14 King E, Ward J, Small L, et al. Athletic groin pain: a systematic review and meta-analysis of surgical versus physical therapy rehabilitation outcomes. Br J Sports Med 2015;49:1447-51.

15 Gore S, Franklyn-Miller A, Richter C, et al. Is stiffness related to athletic groin pain? Scand J Med Sci Sports 2018;28:1681-90.

16 Franklyn-Miller A, Richter C, King E, et al. Athletic groin pain (part 2): a prospective cohort study on the biomechanical evaluation of change of direction. British Journal of Sports Medicine 2016;1-10.

17 Li KC, Higgs J, Aisen AM, et al. MRI in osteoarthitis of the hip: gradations of severity. Magn Reson Imaging 1988;6:229-36.

18 Marshall B, Franklyn-miller A, King E, et al. Biomechanical factors associated with time to complete a change of direction cutting maneuver. J Strength Cond Res 2014;28:2845-51.

19 Kristianslund E, Krosshaug T, Van Den BAJ. Effect of low pass filtering on joint moments from inverse dynamics : implications for injury prevention. J Biomech 2012;45:666-71.

20 Flanagan EP, Comyns TM. The use of contact time and the reactive strength index to optimize fast stretch-shortening cycle training. Strength Cond J 2008;30:32-8.
21 Haff GG, Ruben RP, Lider J, et al. A comparison of methods for determining the rate of force development during isometric mid-thigh clean pulls. J Strength Cond Res.

22 Welch N, Richter C, Moran K, et al. Principal component analysis of the associations between kinetic variables in cutting and jumping, and cutting performance outcome. J Strength Cond Res 2019;1-8.

23 Welch N, Richter C, Franklyn-miller A, et al. Principal component analysis of the biomechanical factors associated with performance during cutting. J Strength Cond Res.

24 Havens KL, Sigward SM. Cutting mechanics: relation to performance and anterior cruciate ligament injury risk. Med Sci Sport Exerc 2015;47:818-24.

25 Hopkins WG, Marshall SW, Batterham AM, et al. Progressive statistics for studies in sports medicine and exercise science. Med Sci Sports Exerc 2009;41:312.

26 Hoffman JR, Maresh CM, Armstrong LE, et al. Effects of off-season and in-season resistance training programs on a collegiate male basketball team. J Hum Muscle Perform 1991;1:48-55. Available http://articles.sirc.ca/search.cfm?id= 341123\%5Cnhttp://ezproxy.spfldcol.edu/login?url=http://search

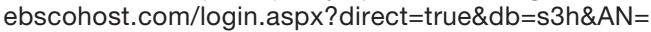
SP341123\&site=ehost-live

27 Counts BR, Buckner SL, Mouser JG, et al. Muscle growth: to infinity and beyond? Muscle Nerve 2017;56:1022-30.

28 Cormie P, McGuigan MR, Newton RU. Developing maximal neuromuscular power: part 2 training considerations for improving maximal power production. Sport Med 2011;41:125-46.

29 Griffin DR, Dickenson EJ, Wall PDH, et al. Hip arthroscopy versus best conservative care for the treatment of femoroacetabular impingement syndrome (UK FASHIoN): a multicentre randomised controlled trial. Lancet 2018;391:2225-35.

30 Wall PD, Dickenson EJ, Robinson D, et al. Personalised hip therapy: development of a non-operative protocol to treat femoroacetabular impingement syndrome in the FASHIoN randomised controlled trial. $\mathrm{Br}$ J Sports Med 2016;50:1217-23.

31 Charlton PC, Drew MK, Mentiplay BF, et al. Exercise interventions for the prevention and treatment of groin pain and injury in athletes: a critical and systematic review. Sport Med 2017;47:2011-26.

32 ÉC F, King E, Kinsella S. Athletic groin pain (part 1): a prospective anatomical diagnosis of 382 patients: clinical findings, MRI findings and patient-reported outcome measures at baseline. Br J Sports Med 2015;1-9. 